\title{
IMPROVING URBAN ACCESSIBILITY: A METHODOLOGY FOR URBAN DYNAMICS ANALYSIS IN SMART, SUSTAINABLE AND INCLUSIVE CITIES
}

\author{
R. PÉREZ-DELHOYO ${ }^{1}$, C. GARCÍA-MAYOR ${ }^{1}$, H. MORA $^{2}$, V. GILART-IGLESIAS ${ }^{2} \&$ \\ M.D. ANDÚJAR-MONTOYA ${ }^{1}$ \\ ${ }^{1}$ Department of Building Sciences and Urbanism, University of Alicante, Spain. \\ ${ }^{2}$ Specialized Processors Architecture Laboratory, Department of Computer Technology and Computation, \\ University of Alicante, Spain.
}

\begin{abstract}
Despite the improvisations of current urban accessibility regulations and their application in urban systems, it is a fact that our cities are not accessible. Both, the assessment of the effectiveness of urban accessibility and its maintenance over time are issues that require a more consistent approach. In order to address these aspects, it is necessary to have an accurate awareness of the existing condition of urban accessibility. Therefore, the way this information is transformed into specific data, which must be collected, stored and assessed, is one of the main challenges that smart cities face. This research helps implement an integrated system for urban accessibility analysis, combining the latest advances in the Information and Communication Technologies, such as RF \& GPS positioning, smart sensing and cloud computing. The main goal of this research is to develop a reliable and effective method to assess public space accessibility with special focus on people with disabilities, by eliciting from users personal experiences. Consequently, the data obtained will enable a better design for improving pedestrian mobility. As a result, a computational architecture for urban dynamics analysis has been designed. Finally, technology and data processing have been validated as an effective system for data collection, and, as a first approach to users' real experience, it has been proposed to have a testing scenario at the University of Alicante,

Keywords: accessibility, computation architecture, inclusive cities, smart cities, smart sensors sustainable cities, technology-aided urban design.
\end{abstract}

\section{INTRODUCTION}

Despite the improvisations of current urban accessibility regulations and their systematic application in urban systems, it is a fact that our cities are not accessible in many cases. People with disabilities, either temporarily or permanently, are still facing an urban environment that is inaccessible, full of obstacles and indifferent to their daily problems [1]. The level of accessibility of urban public spaces absolutely affects the citizens' standard of living and limits their possibilities of enhancing relationships and social integration [2]. That is why, both the assessment of effectiveness of urban accessibility and its maintenance over time, are issues that require a more consistent approach.

In this regard, Information and Communication Technology - ICT - involved in the smart cities concept has much to offer [3,4]. The large development of ICT allows us to interact with an urban environment providing a huge amount of data and information about the cities we live in [5]. A key aspect to deal with regard to the tasks of assessment and maintenance, as well as to detect and manage different problems of accessibility, is to have an accurate awareness about the current state of urban accessibility. This real and updated knowledge on 
urban accessibility will help in improving mobility and liveability of cities and, thereby, the quality of life and welfare of all citizens.

In this context, the United Nations Convention establishes that states are responsible for formulating continuous assessing and monitoring programmes towards achieving equal opportunities for people with disabilities, developing and disseminating technologies related to disability [6]. This approach represents an important change in the understanding of disability and emphasizes the need to include disability as an objective of relevant strategies for sustainable development [7]. Thus, the European Disability Strategy 2010-2020 [8] is currently being developed within the framework of the Europe 2020 Strategy [9], which focuses on enhancing knowledge and innovation, integration and equality, as major pillars for achieving smart, sustainable and inclusive growth. Thus, smart cities concept can make the most of its human capital [10].

In line with this approach, this research implements an integrated system for the analysis of the urban accessibility by integrating it with the latest advances in ICT, such as RF \& GPS positioning, smart sensing and cloud computing. The system proposed is part of the objectives of the European Disability Strategy and exposes the most vulnerable citizens as active participants. In short, the main goal of this research is to develop a methodology to evaluate the accessibility of urban public space from the knowledge of the citizen's own experience, specially focused on people with disabilities.

Consequently, the present work is structured as follows: Section 2 gives an overview of the related work on urban actions and technology used for the analysis of accessibility in cities; Section 3 describes the proposed methodology for improving urban accessibility; Section 4 explains the architecture of the proposed system, based on urban dynamics analysis, and shows the experimentation conducted; and finally, in Section 5, some conclusions are drawn.

\section{RELATED WORK}

\subsection{Urban actions}

The actions carried out to improve urban accessibility have been greatly influenced by European guidelines. Broadly, the actions undertaken at the national, regional and local levels have been classified in three axes established in the European Disability Strategy, which are: awareness, education and information.

However, urban accessibility is an independent matter at the local level. Although national and regional plans have served to define general guidelines and deadlines for action, competent institutions to develop these guidelines and address the specific problems of accessibility have been the city councils at a local level. Theoretically, local accessibility plans have been the most operative instruments. They have been responsible not only for cataloguing the existing barriers in the different municipalities, but also inmaking proposals for their elimination in accordance with current regulations. Increasingly, they are including citizen participation, taking into account social awareness, and have the support of better trained technicians.

Nonetheless, the important legal and regulatory progress and the huge effort, both technical and economical, that has led to the development of local plans have not achieved the expected results. In fact, if we look at the example of Spain, substantial differences have not been reached by the municipalities that have had accessibility plans and those that do not have [11]. This makes it necessary and urgent for a review of the methodologies used up until now. 


\subsubsection{Limitations of the methodologies employed and requirements for a new method to} improve the accessibility of cities

Basically, current methods have been applied in certain urban areas in isolation, without giving importance to maintaining their quality over time. The absence of comprehensive mechanisms to evaluate the effective accessibility of the urban environment, as well as monitoring its evolution, is one of the main weaknesses of the current methodologies. The local application of standards of accessibility is now a common practice. However, the evaluation of its effectiveness has not been consolidated as part of the process.

Likewise, current methodologies have other serious limitations: (1) Many barriers have been identified but the causes or factors that contribute to these barriers have not been analysed. (2) Neither have the modes of behaviour of the different groups to compare and detect inequalities been contemplated. Current methods have been able to determine and quantify certain isolated problems but have not provided the mechanisms to deal with the diversity of citizens. (3) Only static methodologies are always implemented and, therefore, participatory processes have been integrated only partially. Therefore, they have lacked a global strategy.

Thus, a new method to improve the accessibility in cities requires: (1) To move towards proposals with integral features, which are addressed not only to the removal of barriers but also to prevent their occurrence. (2) To provide mechanisms for assessing the current condition of accessibility, as well as monitoring and controling their effectiveness through time. (3) To allow to consolidate the transversal nature of accessibility, and tackle urban and social complexity. (4) To integrate citizen participation into all its mechanisms and processes. (5) To be flexible enough to suit social diversity and nature of the different cities.

Although progress is being made towards models based on encouraging mobility, since the first accessibility plans where implemented, further research is still necessary to endow these models the ability to integrate multiple aspects that can affect urban accessibility. Accessibility can no longer be conceived separately. The concept of city itself demands an integrated approach that fits its spatial complexity and the diversity of its inhabitants [1].

\subsection{Technology used for the analysis of accessibility in cities}

Traditionally, the methods used to obtain information about the status of urban accessibility have been mostly based on surveys [12,13], interviews [14] and audits or direct observation [15]. Other studies have provided mathematical or statistical analysis of these data [16]. In addition, self-reporting tools have allowed for obtaining information from certain places with the collaboration of users [17].

On the other hand, the evaluation of accessibility of urban environments has been mostly associated with processes for informing citizens about the number of urban opportunities. The higher the number of services, the greater the accessibility of an environment, regardless of the capabilities of the user citizens. These processes have been mainly based on the calculation of close relationships and intensities of use, and they have been primarily supported by Global Positioning Systems technologies - GPS - for positioning and Geographic Information Systems - GIS - for displaying data and spatial analysis.

Progressively, the dimension of disability has been taken into account with the introduction of the concepts of absolute and relative access, for measuring time differences in the implementation of specific walks as well as the impact of the elimination of certain obstacles $[18,19]$. The main limitations of these technologies have been associated with differences in scale; they have been valid in specific actions but not effective for the urban scale. 
Accessibility must be incorporated into the city becoming an automatism. Thus, at the present time we face a new challenge: to stop proposing additional technology to the existing design and to begin incorporating it as a part of the urban organism. In this way, urban accessibility finds an optimal scene of opportunity in the context of smart cities. The concepts of ubiquitous and smart cities make use of processing technologies, sensing and communications to provide intelligence to the city while offering connectivity resources, power supply and interoperability [20]. These conditions facilitate the deployment of interconnected smart elements that provide services to citizens for efficient decision-making and to make better use of resources [21].

Increasingly, the methods for assessing the aspects that affect the functioning of the city are based on evidence, i.e. the study of the citizens' behaviours. A good example of this trend is the Information System on the public transport of London [22]. Actually, these participatory processes based on the analysis of urban dynamics are part of a challenging field of research to improve urban accessibility.

\subsubsection{Technologies for urban dynamics analysis}

The most accurate technology to determine the position and deduce the movement is GPS [23], but it only works outdoors and requires the users to allow reporting their position through their devices to a third-party application. In addition, the GPS functionality requires high energy consumption, which means that although it is available on many mobile devices [24], in most cases it is disconnected.

Other wireless communication technologies such as Global System for Mobile communication - GSM - or local area wireless computer networking - WIFI - and Worldwide Interoperability for Microwave Access - WiMax -, also have a high penetration rate in modern societies. Although these networks are not designed for tracking purposes, the paths of the connected devices can be calculated from one base station to another [25]. However, the accuracy offered by these technologies may not be enough. Low Energy Bluetooth beacons - BLE - also enable communication with mobile devices [26]. These latest spread systems require low energy but users also 'have to give permission to access to their mobile devices' can be rephrased as 'have to give permission to access their mobile devices.

An alternative to the above methods is Radio Frequency Identification technology - RFID $[27,28]$. RFID is increasingly being used in the design of user-centric applications, both indoors and outdoors. Furthermore, RF tags are distributed in several formats, such as prepaid plastic cards, tickets, electronic keys and even clothing labels. Several researches have used this kind of technology for tracking people [29-31]. RFID technology neither requires the cooperation of users nor involves energy costs as that of GPS technology. Nonetheless, its scope is not comparable to GPS, because it depends on the position of the antennas and its scope.

The citizen track-and-trace issue is not new as evidenced by the number of researches made. In fact, there is some concern among users and authorities on maintaining the privacy of individuals, due to the large number of devices connected at the users' hands.

\section{PROPOSAL OF A METHODOLOGY FOR IMPROVING URBAN ACCESSIBILITY: OBJECTIVES AND STRATEGIES}

As it was previously specified, after a period of intense legislative development it is a challenge for modern cities to know whether the protection provided by the regulations on urban accessibility is effective or not; and whether its application guarantees people with disabilities the access to urban environments. In order to address this challenge, methodologies that 
recognize whether the implementation of these regulations meets the everyday needs of people with disabilities are needed.

In this regard, the main objective of this research is to design a methodology for assessing the effectiveness of urban accessibility and to monitor its maintenance over time. For this purpose, a system has been designed to measure the real use of public spaces by people with disabilities as well as its evolution. This is an information system about routes, dynamics or patterns of behaviour, which can also be compared with those obtained from people without disabilities.

As a result, not only do we have a real knowledge of the participation of people with disabilities in cities, but a mapping of effective accessibility is also obtained. The main functionalities of the system are described below.

\subsection{Continuous assessment and monitoring of urban accessibility}

A proposed system that addresses the assessment and monitoring of urban accessibility according to three levels of approximation:

\subsubsection{Identification of 'accessible' and 'inaccessible' public urban spaces}

In a first approximation, the system can identify the 'inaccessible' urban pathways and spaces that are either infrequently or never walked by people with disabilities; regardless of being or not adapted to a regulation on accessibility. As well, the system can identify the 'accessible' urban pathways and spaces that, on the contrary, are frequently chosen by people with disabilities.

From this first identification, it is possible to determine the parameters that characterize and qualify, if any, these spaces that are perceived by people with disabilities as 'accessible' or 'inaccessible' spaces in their daily activities.

\subsection{2 'Identification of 'inclusive' public urban spaces}

In a second approximation, the system can recognize the 'inclusive'spaces that are highlighted as magnificent integration environments in the city. These are spaces where people with and without disabilities converge. Such spaces and their characterization - that is, which elements define these spaces - interest us especially in order to reproduce models that are chosen by all individuals and can be applied in the construction and redevelopment of cities.

\subsubsection{Identification of other possible scenes}

In more specific successive scales, the system can identify many other possible scenes. For example, the existence of urban spaces to which, despite intense activity being developed, people with disabilities can never obtain access; or spaces or urban areas where certain groups associated with a particular form of disability feel especially attracted. Or even accessible spaces that with certain frequency turn into inaccessible or just spaces that have permanently lost their accessibility.

These three levels of approximation described are fundamental mechanisms for monitoring and control to ensure continuous assessment and maintenance of effective accessibility in cities.

\subsection{Decision-making in prioritizing actions to improve urban accessibility}

The information recorded in the assessment and maintenance processes also allows addressing a second objective, to support the decision-making to set priorities for improvement actions in 
the public space in the short, medium or long term. A depth analysis not only provides information about the real situation of accessibility but also helps to identify priority elements on which interventions should be carried out because of their influence on the other urban elements and their ability to contribute to improving accessibility in nearby environments.

\section{AN INTEGRATED SYSTEM FOR URBAN DYNAMICS ANALYSIS}

In order to address the assessment of urban accessibility and its maintenance, it is necessary to have an accurate and updated awareness of its current condition. Therefore, the way this information is transformed into specific data is currently a challenge faced by smart cities. In this regard, this research implements an urban accessibility monitoring system based on the urban dynamics analysis, i.e. the study of the movement habits of citizens and the knowledge of their own experience. Specifically, the work is focused on pedestrian mobility, particularly in the most vulnerable group of people with disabilities.

As a result, an integrated system has been designed, which covers the following aspects: first, data collection, i.e. obtaining the citizens' location and experience; secondly, structuring and storage of the information collected; and finally, the collection, comparison and analysis of the flow of citizens' movement. The overall architecture of the proposed system is shown in Fig. 1 and the design aspects of the system are described in the following sections.

\subsection{Method for acquiring citizens' location and experience}

The method is based on the research works [32-34] previously carried out by this research group. The different parts are listed in the following text.

The acquiring architecture corresponds to the distributed part of the overall architecture of the system. The main objective of this infrastructure is to obtain the locations of citizens when they are moving in indoor and outdoor environments of the city. For this purpose, two complementary technologies are used: (1) GPS positioning technology to take advantage of the wide park of phones and wireless devices that this technology incorporates. In this case, the users' collaboration, as well as permission to give their location is required. (2) RFID communication technologies to track and trace citizens. These technologies have increasing implementation and many devices can incorporate it.

The system is based on the automatic reading of citizens' locations. It continuously obtains individual locations through both RFID and GPS technologies. The contents of RFID tags or GPS locations are received by the acquisition devices through the 'Acquisition module'. When a location is received, it is sent to the 'Optimizer module' that is responsible for indicating if the data should be stored or discarded for being redundant. If the information is valid, single locations are stored in the local database - 'Persistent module'. The 'Generating locations message module 'is responsible for monitoring and controlling the optimal number of single locations that are reached to create a message. If so, a location message is created and stored in the local database -'Persistent module'. When 'Location message sender 'detects new messages it starts transmitting by connecting to the central system. When the message is sent and stored in the central system, the system returns a message confirming the reception and the original message is finally deleted from the local system. Finally, through the 'Time synchronization module'the synchronization problem of the system components is solved. In addition, an application for mobile devices has been designed to let users report in real time about their own experience [35]. It is possible to send comments, photos and reports anonymously through it. 


\subsection{Method for structuring and analysing urban accessibility information}

In the central part of the architecture is located the "Accessibility middleware 'that enables the separation of the process of receiving and storing location messages from the process of transformation and information processing included in the messages.

The analysing architecture implements the urban accessibility information service located in the centralized part of the overall architecture of the system. The urban accessibility information service is supported by the Enterprise Service Bus -ESB - integration infrastructure. The results are shown in two ways: according to the paradigm Business to Customer -B2C -, which allows the interaction of users with the system; and according to the paradigm Business to Business - $\mathrm{B} 2 \mathrm{~B}$ - that connects consumers with the system using Web services to improve decision-making. Both protocols can define search filters to supervise a specific urban area.

When the system receives an information search, it begins the process of inference -'Inference module' - consisting of the following steps: (1) citizens' location information, the 'Persistent module,' is structured and completed to build movement flows of citizens -'Citizens' flow generation module'. (2) 'Citizens' flow classification module' analyses the generated routes and creates patterns of behaviour classified by type of disability. To accomplish this, disability types must have been facilitated by people with disabilities -'Persistent module'. (3) These patterns are processed by the 'Citizens' flow comparison module,'which compares the paths of citizens with and without disabilities. In this last step, the final addition is the information of citizens' experience of the application designed for mobile devices -'Persistent module'.

\subsection{Experimentation}

\subsubsection{Technology and data processing validation}

The capabilities of reading technology and data processing have been validated. The design of RFID smart sensor was based on previous researches carried out by this research group [33]. The functionalities to integrate different readings, both RFID and GPS, into the system have been implemented in the cloud using JAVA language. In order to provide data persistence, MySQL community version data base manager has been used. The B2C Presentation

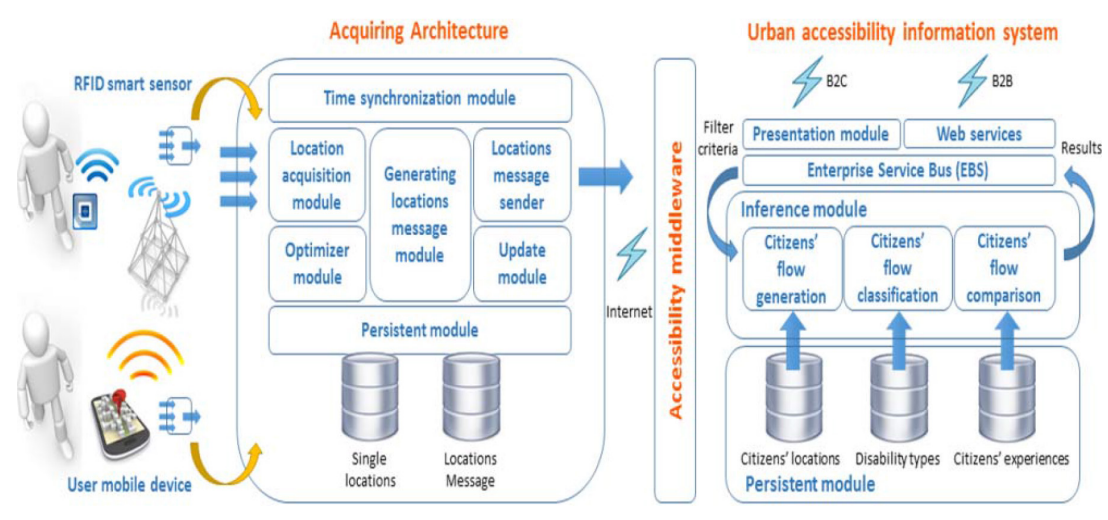

Figure 1: Overall architecture of the system proposed. 
module has been developed through Web technologies such as CSS, HTML5 and JavaScript using node JS framework. For GPS technology, the position messages are received in the service provider through the Internet. There is no problem with simultaneous readings and they are all processed correctly.

\subsubsection{Testing scenario}

Finally, as a first approach to users' real experience, a testing scenario at the University of Alicante has been proposed. However, it was preferred to run a pilot project in a controlled environment, like a campus, before offering more diverse contexts. The aim is to show the capacity of the proposed system to detect accessibility problems.

The cases studied are all outdoors, so the location data have been collected with GPS devices. From this information, the system provides a range of spatial and temporal visualizations allowing the identification of areas with accessibility problems. To show the results, the service uses a web-based user interface from a third-party application - Google Maps JavaScript API v3.

Figure 2 shows one of the environments studied: the path from the concierge of the Polytechnic IV building to the concierge of the Optics building (coordinates: $38.38288,-0.51063$ ). The blue line (A) is the route followed by people with disabilities who need a wheelchair, and the green line $(\mathrm{B})$ is the route followed by people without disabilities. The shortest way is not accessible (A-route length: $196 \mathrm{~m}$; B-route length: $66 \mathrm{~m}$ ).

In the same way, Fig. 3 shows a second environment studied: the path from the concierge of the Germán Bernácer building (coordinates: 38.38288, -0.51063) towards one of the parking of the campus. There is a variation of $35 \mathrm{~m}$ in length between the (A) route in blue and the (B) route in green. The shortest way is not accessible again. The materials used in the construction of the pathway are not appropriate for easy access of people with disabilities who need a wheelchair.

The results shown in Figs 2 and 3 have been obtained by analysing the GPS routes sent to the server through the citizens' mobile devices. The route that is finally shown is the diagram resulting from the combination of the read routes during a period of time. For the purpose of experimentation, it is necessary to count on the cooperation of students with and without disabilities who voluntarily configure their mobile devices to communicate the paths followed inside the campus to our server. Thus, the privacy issues are also avoided.

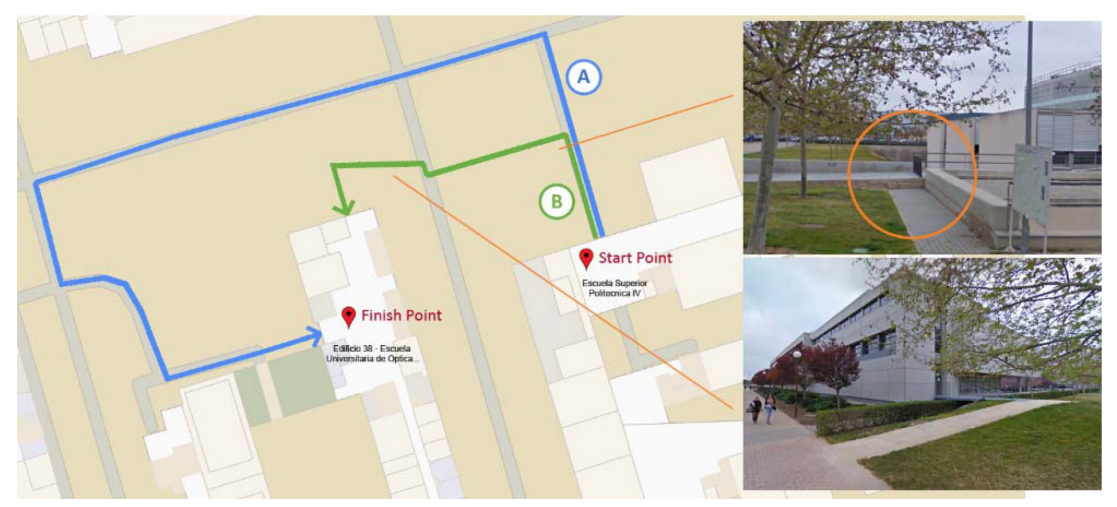

Figure 2: Different routes detected because of problems with movement (1). 


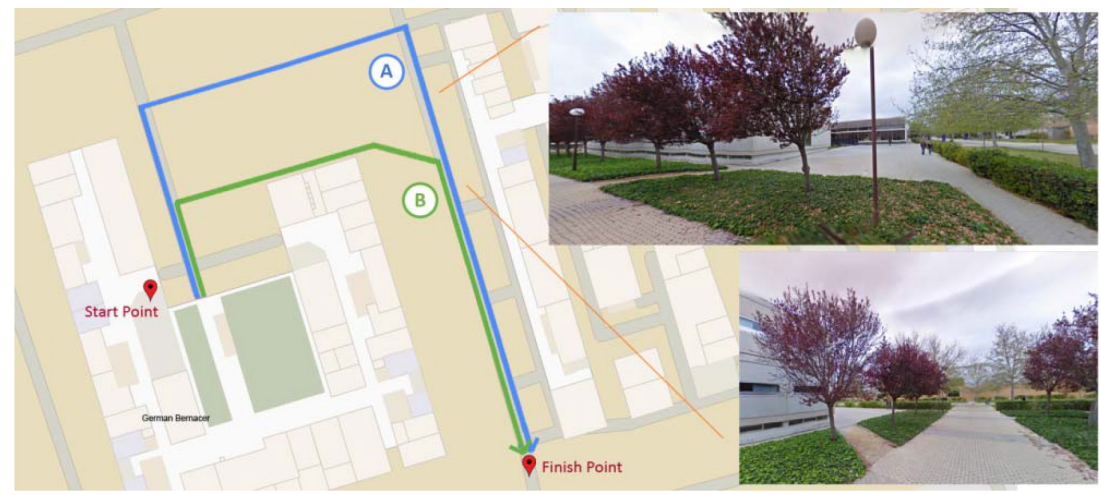

Figure 3: Different routes detected because of problems with movement (2).

\section{CONCLUSIONS}

In the present work a method has been designed, based on the urban dynamics analysis, which allows the evaluation of the effective accessibility in urban environments and the control of its maintenance over time systematically.

The proposed system provides support in making decisions to prioritize improvement actions in public space. It also allows the collection, recording and analysis of spatial data and information about the real state of accessibility. These are all accomplished from the urban operation itself, by including mechanisms to give voice to people with disabilities. The obtained data will enable better design for improving pedestrian mobility in cities.

In this sense, a challenge for future works is to develop this integrated system with channels of information and coordination towards different administrations, associations, professionals, technicians and people with disabilities and society in general.

\section{ACKNOWLEDGEMENTS}

We thank the Association for Integration of Mentally Ill in Alicante and Province - AIEM -, and the Association of People with Cerebral Palsy in Alicante - APCA - "Infanta Elena" Centers, for their support as the Observing Promoter of this project.

\section{REFERENCES}

[1] Joujje, I., Countering the Right to the Accessible City: The Perversity of a Consensual Demand. Cities for All: Proposals and Experiences towards the Right to the City, Habitat International Coalition: Santiago, pp. 43-56, 2010.

[2] Clarke, P., Ailshire, J.A., Bader, M., Morenoff, J.D. \& House, J.S., Mobility disability and the urban built environment. American Journal of Epidemiology, 168, pp. 506-513, 2008.

http://dx.doi.org/10.1093/aje/kwn185

[3] Macagnano, E.V., Intelligent urban environments: towards e-inclusion of the disabled and the aged in the design of a sustainable city of the future. A South African example. Proceeding of the 5th International Conference Sustainable City, 2008. http://dx.doi.org/10.2495/sc080511

[4] Dodgson, M. \& Gann, D., Technological innovation and complex systems in cities. Journal of Urban Technology, 18, pp. 101-113, 2011. http://dx.doi.org/10.1080/10630732.2011.615570 
[5] Bohn, J., Coroama, V., Langheinrich, M., Mattern, F. \& Rohs, M., Living in a world of smart everyday objects-social, economic, and ethical implications. Human and Ecological Risk Assessment: An International Journal, 10, pp. 763-785, 2004. http://dx.doi.org/10.1080/10807030490513793

[6] United Nations, Convention on the Rights of Persons with Disabilities, 2006.

[7] Noga, J. \& Wolbring, G., An analysis of the united nations conference on sustainable development (rio+20) discourse using an ability expectation lens. Sustainability, 5, pp. 3615-3639, 2013.

http://dx.doi.org/10.3390/su5093615

[8] European Commission, European Disability Strategy 2010-2020: A Renewed Commitment to a Barrier-Free Europe, 2010.

[9] European Commission, Europe 2020: A Strategy for Smart, Sustainable and Inclusive Growth, 2010.

[10] Cossetta, A. \& Palumbo, M., The co-production of social innovation: the case of living lab. Smart City. How to Create Public and Economic Value with High Technology in Urban Space, Springer, pp. 221-236, 2014.

[11] Sala, E. \& Alonso, F., La Accesibilidad Universal en los Municipios, Institute for Older Persons and Social Services (IMSERSO): Madrid, 2006.

[12] Beale, L., Field, K., Briggs, D., Picton, P. \& Matthews, H., Mapping for wheelchair users: route navigation in urban spaces. The Cartographic Journal, 43, pp. 68-81, 2006. http://dx.doi.org/10.1179/000870406X93517

[13] Inada, Y., Izumi, S., Koga, M. \& Matsubara, S., Development of planning support system for welfare urban design - optimal route finding for wheelchair users. Procedia Environmental Sciences, 22, pp. 61-69, 2014.

http://dx.doi.org/10.1016/j.proenv.2014.11.006

[14] Hashim, A.E., Samikon, S.A., Ismail, F., Kamarudin, H., Mohd Jalil, M.D. \& Arrif, N.M., Access and accessibility audit in commercial complex: effectiveness in respect to people with disabilities (PWDs). Procedia - Social and Behavioral Sciences, 50, pp. 452-461, 2012.

http://dx.doi.org/10.1016/j.sbspro.2012.08.049

[15] Mackett, R.L., Achuthan, K. \& Titheridge, H., AMELIA: making streets more accessible for people with mobility difficulties. Urban Design International, 13, pp. 81-89, 2008. http://dx.doi.org/10.1057/udi.2008.12

[16] Church, R.L. \& Marston, J.R., Measuring accessibility for people with a disability. Geographical Analysis, 35, pp. 83-96, 2003.

http://dx.doi.org/10.1353/geo.2002.0029

[17] Shigeno, K., Borger, S., Gallo, D., Herrmann, R., Molinaro, M., Cardonha, C., Koch, F. \& Avegliano, P., Citizen sensing for collaborative construction of accessibility maps. Proceeding of the 10th International Conferencce on Web Accessibility, 2013. http://dx.doi.org/10.1145/2461121.2461153

[18] Comai, S., Kayange, D., Mangiarotti, R., Matteucci, M., Ugur Yavuz, S. \& Valentini, F., Mapping city accessibility: review and analysis. Studies Health Technology and Informatics, 217, pp. 325-331, 2015.

[19] Ford, A.C., Barr, S.L., Dawson, R.J. \& James, P., Transport accessibility analysis using gis: assessing sustainable transport in London. International Journal of Geo-Information, 4, 2015.

[20] Yigitcanlar, T., Empirical approaches in knowledge city research. Expert Systems with Applications, 41(12), pp. 5547-5548, 2014.

http://dx.doi.org/10.1016/j.eswa.2014.02.005 
[21] Neirotti, P., Marco, A.D., Cagliano, A.C., Mangano, G. \& Scorrano, F., Current trends in smart city initiatives: some stylised facts. Cities, 38, pp. 25-36, 2014. http://dx.doi.org/10.1016/j.cities.2013.12.010

[22] Ferrari, L., Berlingerio, M., Calabrese, F. \& Reades, J., Improving the accessibility of urban transportation networks for people with disabilities advances. Transportation Research Part C: Emerging Technologies, 45, pp. 27-40, 2014. http://dx.doi.org/10.1016/j.trc.2013.10.005

[23] Bajaj, R., Ranaweera, S.L. \& Agrawal, D.P., GPS: location-tracking technology. Computer, 35(4), pp. 92-94, 2002. http://dx.doi.org/10.1109/MC.2002.993780

[24] Moloo, R.K. \& Digumber, V.K., Low-cost mobile GPS tracking solution. Proceeding of the International Conference on Business Computer and Global Information, IEEE, 2011. http://dx.doi.org/10.1109/bcgin.2011.136

[25] Zhang Y., Li, L. \& Zhang, Y., Research and design of location tracking system used in underground mine based on WiFi technology. Proceeding of the International Forum on Computer Science-Technology and Applications, pp. 25-27, 2009. http://dx.doi.org/10.1109/ifcsta.2009.341

[26] Gómez, C., Oller, J. \& Paradells, J., Overview and evaluation of bluetooth low energy: an emerging low-power wireless technology. Sensors, 12(9), 2012. http://dx.doi.org/10.3390/s120911734

[27] Chawla, V. \& Ha, D.S., An overview of passive RFID. IEEE Communications Magazine, 45(9), pp. 11-17, 2007. http://dx.doi.org/10.1109/MCOM.2007.4342873

[28] Ni, L.M., Zhang, D. \& Souryal, M.R., RFID-based localization and tracking technologies. IEEE Wireless Communications, 18(2), pp. 45-51, 2011. http://dx.doi.org/10.1109/MWC.2011.5751295

[29] Matic, A., Osmani, V. \& Mayora, O., RFID-based system for tracking people: approaches to tagging demented patients. Ambient Media and Systems, 2nd International. ICST Conference, Springer, pp. 60-65, 2011.

[30] Xiong, Z., Song, Z., Scalera, A., Ferrera, E., Sottile, F., Brizzi, P., Tomasi, R. \& Spirito, M.A., Hybrid WSN and RFID indoor positioning and tracking system. EURASIP Journal Embedded Systems, 6, 2013.

[31] Lin, X., Lu, R., Kwan, D. \& Shen, X., REACT: An RFID-based privacy-preserving children tracking scheme for large amusement parks. Computer Networks, 54, 2010.

[32] Mora, H., Gil, D., Lopez, J.F.C., Pont, M.T.S., Flexible framework for real-time embedded systems based on mobile cloud computing paradigm. Mobile Information Systems, 2015. http://dx.doi.org/10.3390/s150613591

[33] Mora-Mora, H., Gilart-Iglesias, V., Gil, D. \& Sirvent-Llamas, A., A computational architecture based on RFID sensors for traceability in smart cities. Sensors, 15(6), pp. 13591-13626, 2015.

[34] Gilart-Iglesias, V., Mora, H., Perez-delHoyo, R. \& Garcia-Mayor, C., A computational method based on radio frequency technologies for the analysis of accessibility of disabled people in sustainable cities. Sustainability, 7(11), pp. 14935-14963, 2015. http://dx.doi.org/10.3390/su71114935

[35] Mora, Higinio. et al. Interactive cloud system for the analysis of accessibility in smart cities. International Journal of Design \& Nature and Ecodynamics, 2016. 